\title{
New Simple 3-Dimensional Computed Tomogram Classification Leading to Successful Conservative Treatment in 51 Atlanto-Axial Rotatory Fixation Children
}

\author{
Jong Yeon Kim ${ }^{\mathrm{a}}$ Jae Ho Cho ${ }^{\mathrm{b}}$ Soo Han Yoon ${ }^{\mathrm{c}}$ Sung Min Cho ${ }^{\mathrm{a}}$ \\ Yong Cheol Lim ${ }^{c}$ \\ aDepartment of Neurosurgery, Wonju Severance Christian Hospital, Yonsei University Wonju College of \\ Medicine, Wonju, Republic of Korea; ${ }^{b}$ Department of Orthopedic Surgery, Ajou University School of \\ Medicine, Suwon, Republic of Korea; 'Department of Neurosurgery, Ajou University School of Medicine, \\ Suwon, Republic of Korea
}

\section{Keywords}

Pediatric cervical spine - Atlanto-axial rotatory fixation .

Atlanto-axial subluxation - Cervical collar · Cervical traction . Three-dimensional computed tomography

\begin{abstract}
Objective: to present a new and easy classification of atlanto-axial rotatory fixation (AARF) and to investigate the efficiency of conservative treatment of AARF. Background: Although there is a precise definition and diagnostic classification of AARF, there is still significant difficulty in measuring the atlas and axis angles because all of the atlas or axis cannot be seen in a certain 2-dimensional computed tomogram image. In addition, some recent case reports showed that long-term conservative treatment can reduce pediatric AARFs, even that are severe or chronic. Methods: Fifty-one children with AARF were analyzed retrospectively with new 3-dimensional computed tomogram (3DCT)-based AARF classification; the mean age was $72.7 \pm 35.2$ months (19-139 months). In the new AARF classification, type 1 was defined as that when the $\mathrm{C} 1 \mathrm{C} 2$ angle is not $0^{\circ}$ on midline and type 2
\end{abstract}

as that when the $\mathrm{C} 1 \mathrm{C} 2$ angle is $0^{\circ}$ on the midline. Results: All 7 children with AARF type 1 were treated successfully only with Halter tractions. Twenty among 44 children with type 2 did not show any difference in improvement compared with not-treated 24 children with type 2. Conclusion: The first new AARF classification based on 3DCT appears to be easy to use and even the most severe children with AARF may be managed only with conservative treatment such as longterm Halter traction.

(c) 2021 S. Karger AG, Basel

\section{Introduction}

Atlanto-axial rotatory fixation (AARF) is defined as the pathological fixation of the axis and atlas during horizontal rotation, of which there are several theoretical etiologies [ 1 , 2]. AARF is extremely rare in adults and arises mainly in children and may be preceded by external trauma, upper tract respiratory infections, genetic diseases such as Down's syndrome, Morquio's syndrome, Marfan's syndrome, and cranial or cervical spine surgery [2-6]. 
Table 1. Patient characteristics in 52 children with AARF

\begin{tabular}{|c|c|}
\hline Parameter & $\begin{array}{l}\text { Mean } \pm \text { standard } \\
\text { deviation, } n(\%)\end{array}$ \\
\hline \multicolumn{2}{|l|}{ Sex } \\
\hline Boy & $31(60.8)$ \\
\hline Girl & $20(39.2)$ \\
\hline \multicolumn{2}{|l|}{ Growth } \\
\hline Age, months & $72.7 \pm 35.2$ \\
\hline Weight, kg & $22.8 \pm 11.3$ \\
\hline \multicolumn{2}{|l|}{ Causes } \\
\hline Trauma & $20(39.2)$ \\
\hline Upper respiratory infection & $13(25.5)$ \\
\hline Usual life activity & $13(25.5)$ \\
\hline Unknown & $5(9.8)$ \\
\hline \multicolumn{2}{|l|}{ Mean symptom duration, days } \\
\hline All $(n=51)$ & $16.3 \pm 58.6$ \\
\hline Type $1(n=7)$ & $123 \pm 132$ \\
\hline Type $2(n=44)$ & $1 \pm 3$ \\
\hline \multicolumn{2}{|l|}{ Treatment - Halter traction } \\
\hline \multicolumn{2}{|l|}{ Type 1} \\
\hline Patient's number & 7 \\
\hline Mean duration, days & $35.4 \pm 18.1$ \\
\hline Mean traction weight, $\mathrm{lb}$ & $2.4 \pm 0.6$ \\
\hline \multicolumn{2}{|l|}{ Type 2} \\
\hline Patients, $n$ & 20 \\
\hline Mean duration, days & $11.5 \pm 8.3$ \\
\hline Mean traction weight, lb & $1.5 \pm 0.7$ \\
\hline \multicolumn{2}{|l|}{ Follow-up } \\
\hline Patients, $n$ & $42(82.4)$ \\
\hline Mean duration, weeks & $11.3 \pm 17.7$ \\
\hline
\end{tabular}

AARF, atlanto-axial rotatory fixation.

AARF is a state in that there is pathology of the atlas and the axis rotation rather than flexion-extension. The concept of the rotation angles of the atlas and axis was first developed by Li and Pang [2] who diagnosed and classified AARF using dynamic 2-dimensional computed tomography (2DCT). In reality, however, dynamic 2DCT imaging of the atlas and axis does not show the entire configuration of the atlas and axis in a single image plane [7]. Therefore, the images of the atlas and axis must be interpreted using multiple planes in order to measure the rotation angles of the atlas and axis.

The treatment for AARF pediatric patients with mild types or those with symptoms lasting $<1$ month consists of primary application of a Halter traction or a cervical collar [2, 8-11]. Skeletal traction or a halo vest may be considered for patients with severe types or symptoms lasting $>1$ month, while the decompression surgery or atlanto-axial fusion can be conducted for those in whom
Table 2. Authors' classification of AARF on 3DCT

\begin{tabular}{|c|c|}
\hline uthors' & ification \\
\hline Type 1 & \\
\hline $\mathrm{C} 1 \mathrm{C} 2 \mathrm{a}$ & $e$ is not $0^{\circ}$ on midline \\
\hline 1a & C1 cannot cross over midline \\
\hline $1 \mathrm{~b}$ & $\mathrm{C} 1$ cross over midline but not override $\mathrm{C} 2$ \\
\hline $1 \mathrm{c}$ & $\begin{array}{l}\mathrm{C} 1 \text { can override } \mathrm{C} 2 \text {, but } \mathrm{C} 1 \mathrm{C} 2 \text { angle is not } 0^{\circ} \text { on } \\
\text { midline }\end{array}$ \\
\hline Type 2 & \\
\hline $\mathrm{C} 1 \mathrm{C} 2 \mathrm{a}$ & $\mathrm{e}$ is $0^{\circ}$ on midline \\
\hline $2 \mathrm{a}$ & $\mathrm{C} 2 \mathrm{C} 3$ angle $<0^{\circ}$, bilateral \\
\hline $2 \mathrm{~b}$ & $\mathrm{C} 2 \mathrm{C} 3$ angle $<0^{\circ}$, unilateral \\
\hline Normal & \\
\hline $\mathrm{C} 1 \mathrm{C} 2 \mathrm{a}$ & $\mathrm{e}$ is $0^{\circ}$ on midline \\
\hline $\mathrm{C} 2 \mathrm{C} 3 \mathrm{a}$ & e $>0^{\circ}$, bilateral \\
\hline
\end{tabular}

AARF, atlanto-axial rotatory fixation; 3DCT, 3-dimensional computed tomogram.

the above treatment has failed $[2,4,5,9,11]$. In contrast, recent reports have introduced the new trend in practice that prefer the simple halter traction, even for the patients with severe types or symptoms lasting $>3$ months $[7,12$, 13]. Therefore, the goal of this article is to develop a simpler and easier diagnostic classification and new treatment algorithms for pediatric patients with AARF.

\section{Materials and Methods}

From January 2004 to December 2016, the radiologic images and medical records of 61 pediatric patients under age of 12 years, with symptoms of cervical pain and neck rotation, and who had underwent dynamic 3-dimensional computed tomogram (3DCT) were analyzed retrospectively. Patients who did not receive 3DCT at the initial hospital visit and those with spinal fractures or congenital anomalies were excluded. The final 51 children comprised 31 males and 20 females; the mean age was $72.7 \pm 35.2$ months (19-139 months) (Table 1).

The dynamic 3DCT scans were conducted in 3 different positions (neutral, left rotation, and right rotation) as the dynamic 2DCT of Pang and Li [10]. The authors present a new dynamic 3DCT-based AARF classification consisting of 2 types and 5 subtypes (Table 2). In the new dynamic 3DCT-based AARF classification, type 1 was defined as that when the atlas does not override the axis or the $\mathrm{C} 1 \mathrm{C} 2$ angle is not $0^{\circ}$ on midline (Fig. 1). Type 1 was further divided into 3 subtypes (Fig. 2). Type 2 was defined as the atlas that overrides and the $\mathrm{C} 1 \mathrm{C} 2$ angle is $0^{\circ}$ on the midline (Fig. 1). Type 2 was further divided into 2 subtypes depending on presence of unilateral or bilateral abnormal negative $\mathrm{C} 2 \mathrm{C} 3$ angle (opposite rotation of $\mathrm{C} 2$ compared to $\mathrm{C} 3$ ) (Fig. 3): type 2a was defined as that when bilateral abnormal negative $\mathrm{C} 2 \mathrm{C} 3$ angle and type $2 \mathrm{~b}$ was defined as when unilateral abnormal negative C2C3 angle (Fig. 4). 
Fig. 1. Posterior view diagrams of cranium (tan color), C1 (sky blue color), and C2 (papaya whip color) for $\mathrm{C} 1 \mathrm{C} 2$ angle in the neutral position. In the neutral position, when the $\mathrm{C} 1$ and $\mathrm{C} 2$ spinal processes indicated by the midline (red line) do not align, the $\mathrm{C} 1 \mathrm{C} 2$ angle (blue arrow line) is defined as $>0$ (a) and the $\mathrm{C} 1 \mathrm{C} 2$ angle (blue arrow line) as 0 when the midline (red line) are aligned (b).

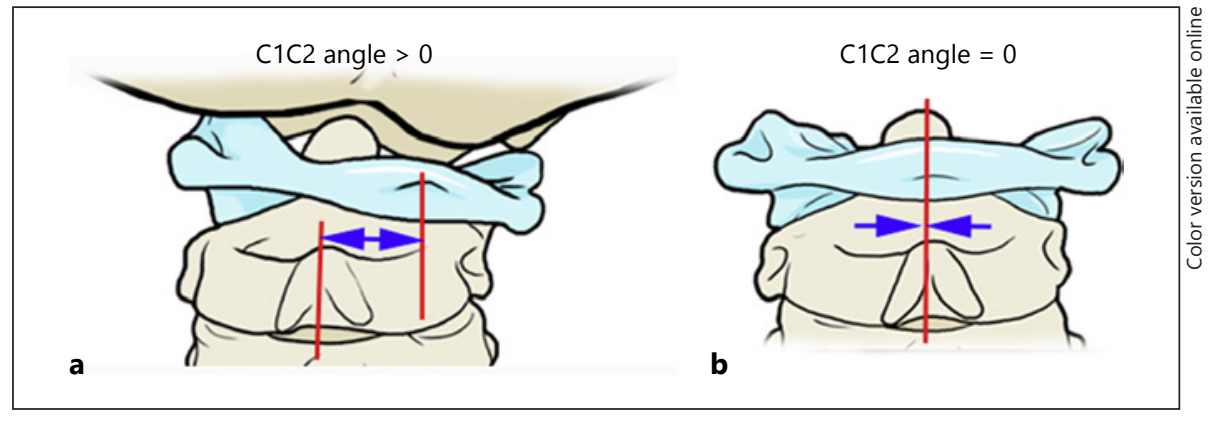

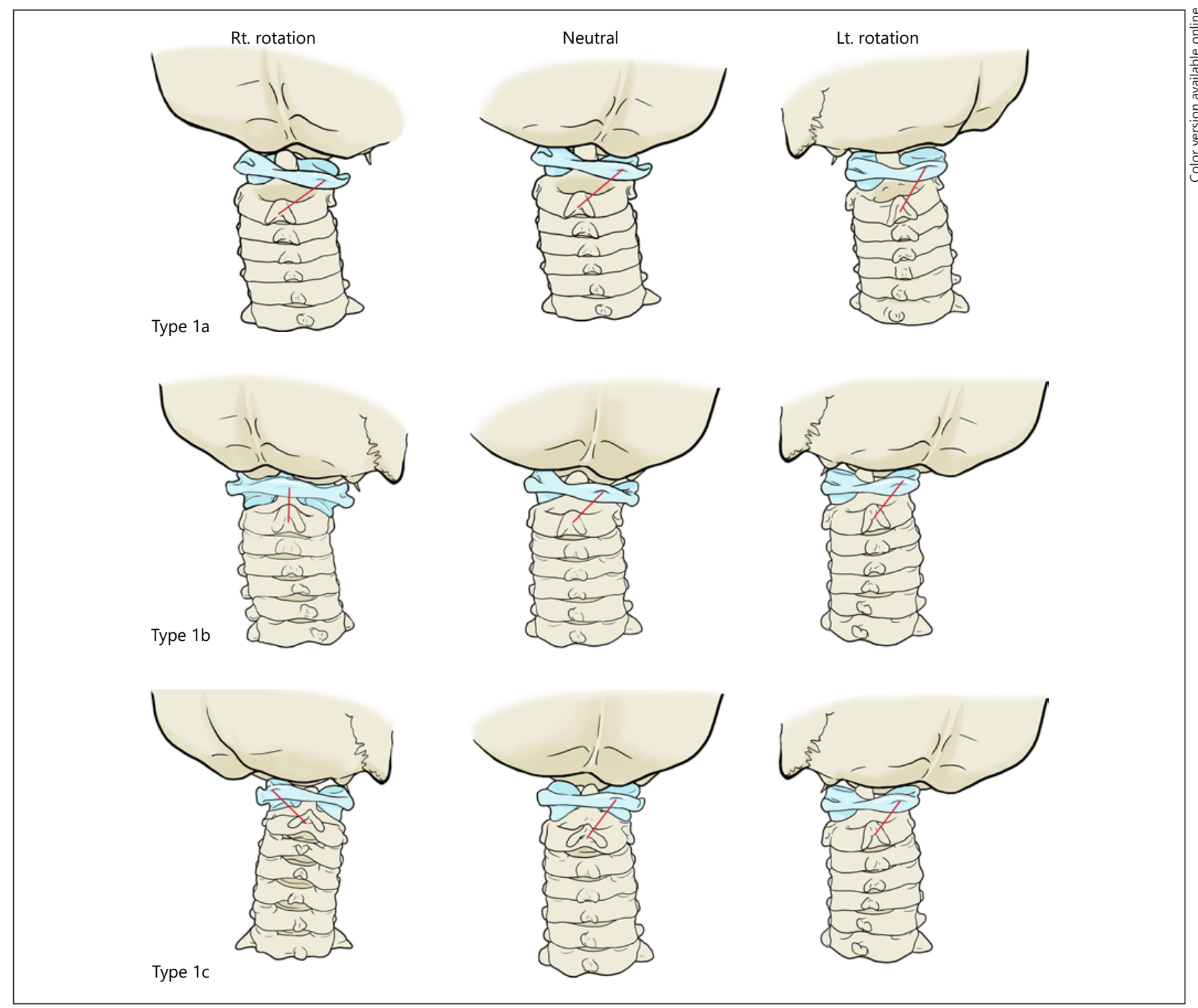

Fig. 2. Posterior view diagrams of 3 type 1 AARF subtypes. The first row shows cervical spine 3DCT images of the child with type 1a where $\mathrm{C} 1$ cannot cross over midline. The second row shows cervical spine 3DCT images of the child with type $1 \mathrm{~b}$ where $\mathrm{C} 1 \mathrm{can}$ cross over midline but not override $\mathrm{C} 2$. The third row shows cervi- cal spine 3DCT images of the child with type $1 \mathrm{c}$ where $\mathrm{C} 1$ can override $\mathrm{C} 2$ but $\mathrm{C} 1 \mathrm{C} 2$ angle is not on midline. The imaginary line (red color) of the posterior middle of $\mathrm{C} 1$ and $\mathrm{C} 2$ showed clear understanding for the rotation of $\mathrm{C} 1$ and $\mathrm{C} 2$. AARF, atlanto-axial rotatory fixation; 3DCT, 3-dimensional computed tomogram. 
Fig. 3. Posterior view diagrams of $\mathrm{C} 1$ (blue color) and C2 (papaya whip color) for $\mathrm{C} 2 \mathrm{C} 3$ alinement in the rotation position. In the rotation position, the $\mathrm{C} 2 \mathrm{C} 3$ angle (blue arrow) is defined as $<0$ when the $\mathrm{C} 1$ and $\mathrm{C} 3$ spinal process as indicated by the midline (red lines) rotation is in the opposite direction of the $\mathrm{C} 2$ rotation as indicated by the midline (green line) (a), and when the C1(red line), C2 (green line), and C3 (red line) all rotated in the same direction the $\mathrm{C} 2 \mathrm{C} 3$ angle (black arrow) was defined as $>0$ (b).

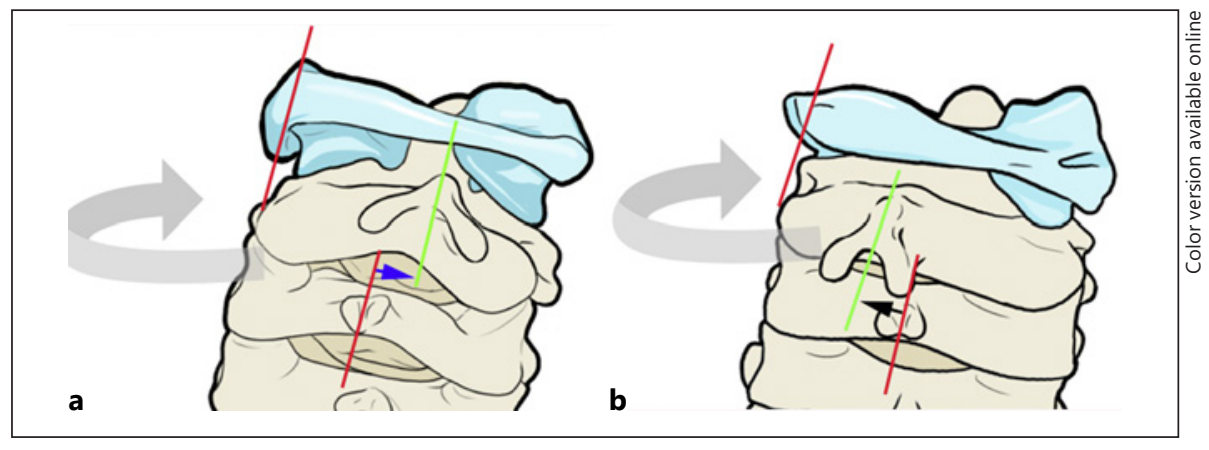

Treatment consisted of medication with or without the application of a cervical collar and Halter traction. Halter traction was intermittently administered with a repeated sequence of rest (30-40 $\min$ ) and traction (20-30 $\mathrm{min})$. No traction was applied during sleeping. The initial traction weight was set at about $2-3 \%$ of the body weight and was increased to $5-10 \%$ of body weight $(1-5 \mathrm{lb})$. In 27 pediatric patients, Halter traction with a mean weight $1.8 \pm$ $0.8 \mathrm{lb}$ was administered for a mean period of $18.6 \pm 15.6$ days. The 42 patients received $4.2 \pm 5.1$ weeks of cervical collar therapy. All 51 children were followed up for a mean period of $11.3 \pm 17.7$ weeks.

\section{Statistical Analysis}

Among the 44 type 2 children, we compared 20 children who received Halter traction with 24 children who did not with respect to symptomatic and/or type improvement. Statistical analyses were performed using a $\chi$ test, and $p$ values and 95\% confidence intervals were calculated.

\section{Results}

When the 51 pediatric AARF patients were classified by the new classification based on dynamic 3DCT, 7 were classified as type 1 and 44 as type 2 (Table 3 ). Patients were further classified into subtypes: 5 patients were classified as type $1 \mathrm{a}, 1$ as type $1 \mathrm{~b}, 1$ as type $1 \mathrm{c}, 20$ as type $2 \mathrm{a}$, and 25 as type $2 b$.

All 7 children with AARF type 1 were treated successfully only with Halter tractions for $32.0 \pm 17.1$ days (weight $2.3 \pm 0.6 \mathrm{lb}$ ). Three type 1 patients received $8-10$ weeks of 2-3-lb weight Halter traction and thereafter improved to type 2 . Three other type 1 children received 2-3-lb weight Halter traction for 3-8 weeks and improved to type 2. Last, one type 1 child received 4 weeks of a mean 2.5 -lb weight Halter traction and remained as type 1 but improved symptomatically and was lost to follow-up. Among the 44 type 2 children, 20 received Halter traction for a mean of $11.5 \pm 8.3$ days with a mean weight of $1.5 \pm 0.7 \mathrm{lb}$, and 24 children did not receive Halter traction, but all 44 children demonstrated improvement without significant differ-
Table 3. Follow-up results of 51 AARF children according to the author's classification

\begin{tabular}{lll}
\hline $\begin{array}{l}\text { Initial types } \\
\text { (Patient, } n)\end{array}$ & $\begin{array}{l}\text { Follow-up types } \\
\text { after } 1 \text { month }\end{array}$ & $\begin{array}{l}\text { Follow-up types } \\
\text { after } 3 \text { months }\end{array}$ \\
\hline Type $1(3)$ & Type 1 & Type 2 \\
Type $1(3)$ & Type 2 & Type 2 \\
Type $1(1)$ & Type $1^{*}$ & \\
Type 2 $(43)$ & Type 2** & Type $1^{* * *}$ \\
Type 2 $(1)$ & Type 2 & \\
\hline
\end{tabular}

AARF, atlanto-axial rotatory fixation. * This patient was improved symptomatically but transferred to another hospital during treatment and not followed up after 1 month. ${ }^{* *}$ All children were improved symptomatically. ${ }^{* * *}$ A child who was initially classified as type 2 recurred as type 1c 2 years later and improved again.

ence with respect to Halter traction. In 1 exceptional case, a child who was initially classified as type 2 recurred as type $1 \mathrm{c} 2$ years later and improved again to type $2 \mathrm{~b}$ with 2 weeks of 3-lb weight Halter traction (Table 3).

\section{Discussion}

\section{$A A R F$ Diagnosis and Classification}

AARF was first described by Corner [14] in 1907, who named the condition "rotatory dislocation of the atlas." In 1930, Grisel [15] reported that patients with a pharyngeal infection followed by persistent torticollis symptoms developed atlanto-axial subluxation that was called Grisel's syndrome. In 1968, Wortzman and Dewar [16] first coined the term AARF.

In 1977, Fielding and Hawkins [1] reported the diagnosis and classification of AARF under the concept of atlanto-axial subluxation based on measurements of the atlanto-dental interval on simple cervical X-ray imaging. 


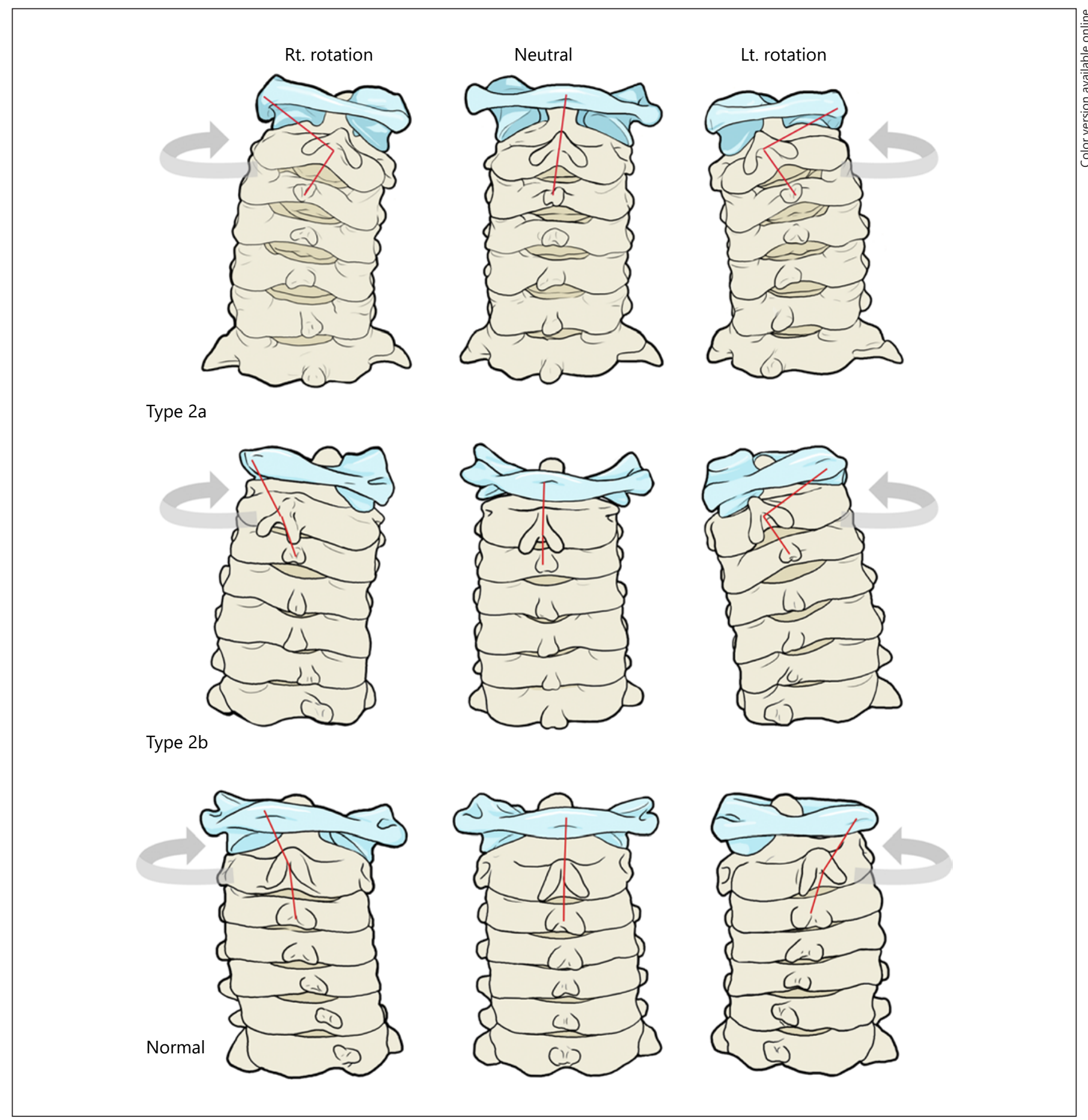

Fig. 4. Posterior view diagrams of 3 type 2 AARF subtypes. The first row shows cervical spine 3DCT images of child with type $2 \mathrm{a}$ where $\mathrm{C} 1 \mathrm{C} 2$ angle is $0^{\circ}$ on midline but bilateral C2C 3 angle $<0^{\circ}$. The second row shows cervical spine 3DCT images of the child with type $2 \mathrm{~b}$ where $\mathrm{C} 1 \mathrm{C} 2$ angle is $0^{\circ}$ on midline but unilateral $\mathrm{C} 2 \mathrm{C} 3$ angle $<0^{\circ}$. The third row shows cervical spine 3DCT images of the child with normal rotation where $\mathrm{C} 1 \mathrm{C} 2$ angle is $0^{\circ}$ on midline and bilateral $\mathrm{C} 2 \mathrm{C} 3$ angle $>0^{\circ}$. The imaginary line (red color) of the posterior midline of $\mathrm{C} 1, \mathrm{C} 2$, and C3 shows clear understanding for the rotation of $\mathrm{C} 1, \mathrm{C} 2$, and $\mathrm{C} 3$. AARF, atlanto-axial rotatory fixation; 3DCT, 3-dimensional computed tomogram. 
Fielding et al. [17] were the first to consider 2DCT imaging for the diagnosis of atlanto-axial subluxation.

Li and Pang [2] in 1995 presented the first study using dynamic 2DCT imaging for the classification of AARF. Type 1 was defined as the uniform fixation of the atlantoaxial angle during head rotation, type 2 as a reduction of the atlanto-axial angle during rotation in the opposite direction. Thereafter, Pang and Li [5] revised a more detailed 5-step classification in 2005. In addition to 2DCT imaging, Ishii et al. [18] in 2012 was the first to report the application of 3DCT imaging in the diagnosis of AARF which could directly visualize atlanto-axial joint subluxation but was not used in the diagnosis or classification of AARF.

\section{AARF Treatment}

The frequency of AARF is low and the majority of patients experience improvement of symptoms without therapy or only with conservative management $[2,6,10$ 13]. In some cases, manual repositioning under general anesthesia followed by the application of a cast has been performed, even in the acute phase [19].

If symptoms persist for longer than the duration of acute phase, which is $1-3$ months, cranial traction with halo vest or brace, or surgical treatments such as atlantoaxial reduction, atlanto-axial fusion, odontoidectomy and occipito-cervical fusion, transoral reduction and posterior atlanto-axial fusion, and occiput- $\mathrm{C} 2$ pedicle polyaxial screw stabilization may be required $[2,5,19-26]$.

\section{New 3DCT-Based AARF Diagnosis and Classification}

Dynamic 2DCT imaging fails to show the atlas and axis in a single image but only in several different and separate images. However, the present authors' 2-type classification should be very simple and easy to use because the differential point between severe (type 1) and mild (type 2) is only whether the $\mathrm{C} 1 \mathrm{C} 2$ angle is $0^{\circ}$ on the midline or not. Therefore, to diagnose a child as type 1 , dynamic computed tomogram (CT) is unnecessary and only a simple neutral 3DCT is required. The dynamic 3DCT is necessary in later subtyping of type 1 only for a small number of patients with persistent symptoms even after 1 month of Halter traction. Type 2 is much more commonly diagnosed only with a simple neutral 3DCT than type 1 so that all subtyping of type 2 is unnecessary and only radiographic description in my experience. Therefore, this 3DCT classification method with neutral 3DCT only can expose less radiation in most cases than Pang's dynamic 2DCT classification method requiring both neutral and dynamic CT. This decreased radiation

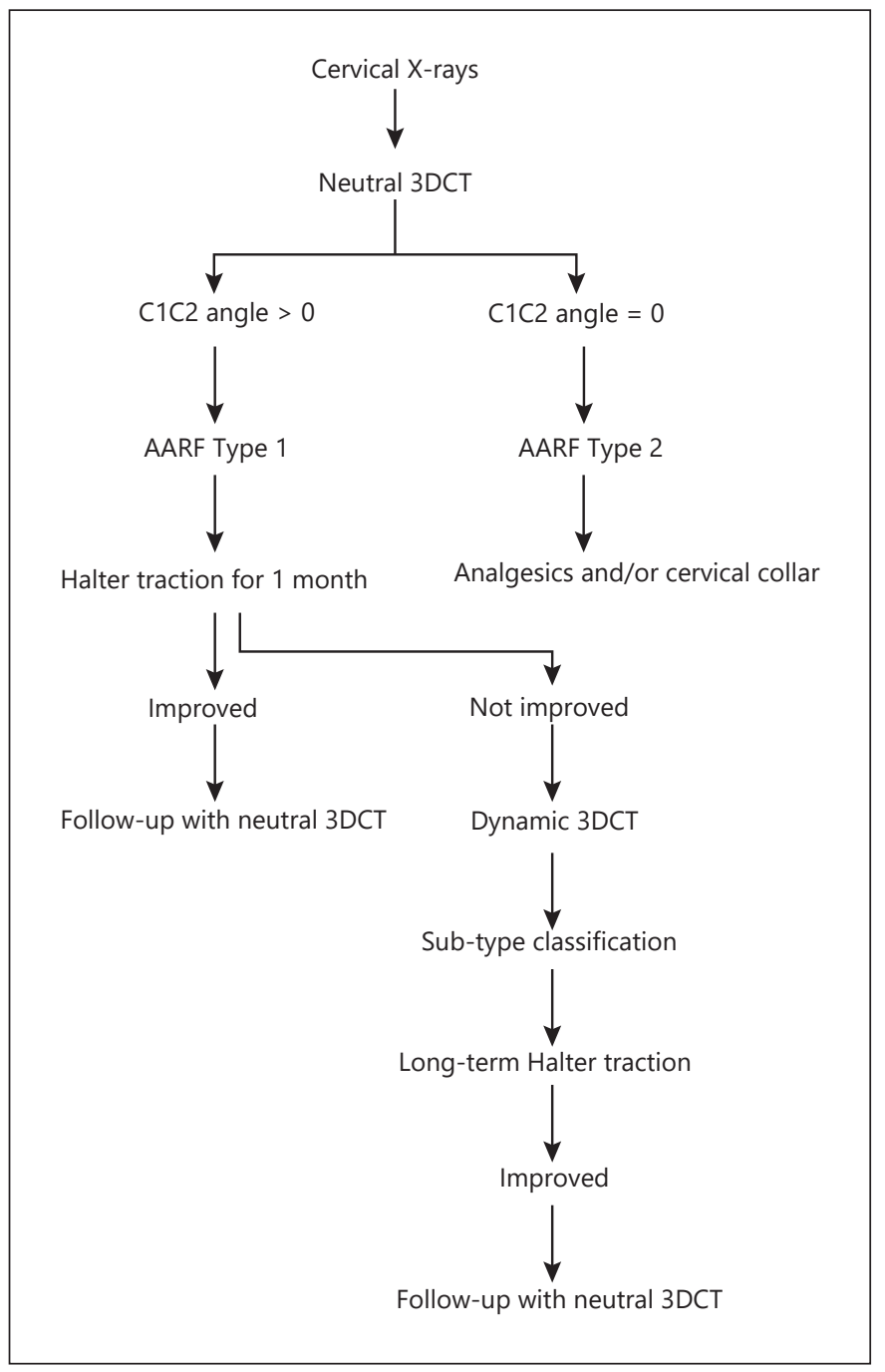

Fig. 5. The authors' diagnostic and treatment algorithm for pediatric AARF patients. A neutral 3DCT imaging procedure is conducted in all patients but additionally 2 rotational 3DCT imaging procedures are only performed in among those who showed that $\mathrm{C} 1 \mathrm{C} 2$ angle is not zero degree on the neutral 3DCT imaging. AARF, atlanto-axial rotatory fixation; 3DCT, 3-dimensional computed tomogram.

exposure is important in patients with AARF because almost AARF patients are children sensitive to radiation.

\section{New Diagnosis and Treatment Algorithm Based on the 3DCT AARF Classification}

Patients with severe and a long duration of AARF have been managed by skeletal traction or surgical treatment. However, recent reports suggest that pediatric patients with symptom lasting 3 months can be managed successfully by simple Halter traction $[7,13]$. We agree this con- 
cept of simple Halter traction treatment is suitable even for severe and chronic AARF. We also compared 20 (45.5\%) children with type 2 AARF who received Halter traction with 24 children with type 2 AARF who did not receive traction, and our results showed all improved with no statistical difference. This supports that children with type 2 can be sufficiently treated with cervical collar and medication. We have incorporated the results of this study in the diagnostic and treatment algorithm shown in Figure 5.

According to Pang and Li [5], in their study of 50 pediatric AARF patients, 13 (26\%) experienced recurrent disease while Crossman et al. [21] in 2004 reported only 4 recurrences over a 15-year period, the latter being corroborated by other authors who reported no recurrences $[25$, 27]. In the present study, a type 2 a child (1/51) suffered recurrent symptom attack, 2 years after therapy, that aggravated to type $1 \mathrm{c}$ and then improved again to type 2 . We believe that recurrent AARF is very rare, and may be treated adequately by Halter traction only if recurrence occurs.

\section{Limitation in This Study}

Even though all type 1 children with long duration of $>3$ months and up to 1 year were successfully recovered only with simple long-term Halter traction, patients with type 1 numbered only 7 so that we cannot absolutely conclude that all type 1 children can be treated only with Halter traction. However, we believe that simple long-term Halter traction should be considered before surgical correction.

\section{Conclusion}

In this study of 51 AARF pediatric patients, the first new 3DCT classification is simpler and easier than the 2DCT classification. Nonsurgical therapies, such as long- term Halter traction or cervical collars, are adequate for the management of most children with AARF.

\section{Acknowledgement}

The authors wish to thank Dr. Chang $\mathrm{KH}$ for preparing the English version manuscript of this paper.

\section{Statement of Ethics}

This retrospective study was approved by the University Hospital Institutional Review Board (AJIRB-MED-OBS-15-174). Written informed consent from the patients (or their parents or guardians) was not obtained as the study was designed as a retrospective study that does not publicize any personal medical data, and both the institutional/national code and World Medical Association Declaration of Helsinki do not require written informed consent in retrospective studies.

\section{Conflict of Interest Statement}

The authors have no conflicts of interest to declare.

\section{Funding Sources}

The authors have no funding source.

\section{Author Contributions}

Yoon conceived, designed, and supervised the study; Kim conducted the literature review, analyzed data, and wrote the manuscript; Cho J.H. and Cho S.M. collected the data and wrote the manuscript; Lim conducted the analyses and wrote the manuscript.

\section{References}

1 Fielding JW, Hawkins RJ. Atlanto-axial rotatory fixation. (Fixed rotatory subluxation of the atlanto-axial joint). J Bone Joint Surg Am. 1977;59(1):37-44.

$2 \mathrm{Li} \mathrm{V}$, Pang D. Atlantoaxial rotatory fixation. In: Pang D, editor. Disorders of the pediatric spine. New York, NY: Raven Press; 1995. p. 531-53.

3 Herzka A, Sponseller PD, Pyeritz RE. Atlantoaxial rotatory subluxation in patients with Marfan syndrome: a report of three cases. Spine. 2000;25:524-6.

4 Moore KR, Frank EH. Traumatic atlantoaxial rotatory subluxation and dislocation. Spine. 1995;20(17):1928-30.
5 Pang D, Li V. Atlantoaxial rotatory fixation: part 3-A prospective study of the clinical manifestation, diagnosis, management, and outcome of children with atlantoaxial rotatory fixation. Neurosurgery. 2005;57:954-72.

6 Wetzel FT, La Rocca H. Grisel's syndrome. Clin Orthop. 1989;240:141-52.

7 Park SW, Cho KH, Shin YS, Kim SH, Ahn YH, Cho KG, et al. Successful reduction for a pediatric chronic atlantoaxial rotatory fixation (Grisel syndrome) with long-term halter traction: case report. Spine. 2005;30:E444-9.

8 Maheshwaran S, Sgouros S, Jeyapalan K, Chapman S, Chandy J, Flint G. Imaging of childhood torticollis due to atlanto-axial rota- tory fixation. Childs Nerv Syst. 1995;11(12): 667-71.

9 Martinez-Lage JF, Martinez Perez M, Fernandez Cornejo V, Poza M. Atlanto-axial rotatory subluxation in children: early management. Acta Neurochir. 2001;143(12):1223-8.

10 Pang D, Li V. Atlantoaxial rotatory fixation: part 2-new diagnostic paradigm and a new classification based on motion analysis using computed tomographic imaging. Neurosurgery. 2005;57:941-53.

11 Subach BR, McLaughlin MR, Albright AL, Pollack IF. Current management of pediatric atlantoaxial rotatory subluxation. Spine. 1998;23(20):2174-9. 
12 Fernandez Cornejo VJ, Martinez-Lage JF, Piqueras C, Gelabert A, Poza M. Inflammatory atlanto-axial subluxation (Grisel's syndrome) in children: clinical diagnosis and management. Childs Nerv Syst. 2003;19:342-7.

13 Hsu PT, Chung HY, Wang JL, Lew HL. Successful conservative treatment of chronic atlantoaxial rotatory fixation in a child with torticollis. Am J Phys Med Rehabil. 2010;89(9): 776-8.

14 Corner EM. Rotary dislocations of the atlas. Ann Surg. 1907;45(1):9-26.

15 Grisel P. Enucléation de l'atlas et torticolis naso-pharingien. Presse Med. 1930;38:50-3.

16 Wortzman G, Dewar FP. Rotary fixation of the atlantoaxial joint: rotational atlantoaxial subluxation. Radiology. 1968;90(3):479-87.

17 Fielding JW, Hawkins RJ, Hensinger RN, Francis WR. Atlantoaxial rotary deformities. Orthop Clin North Am. 1978;9(4):955-67.

18 Ishii K, Toyama Y, Nakamura M, Chiba K, Matsumoto M. Management of chronic atlantoaxial rotatory fixation. Spine. 2012; 37(5):E278-85.
19 Pilge H, Holzapfel BM, Lampe R, Pilge S, Prodinger PM. A novel technique to treat Grisel's syndrome: results of a simplified, therapeutical algorithm. Int Orthop. 2013; 37(7):1307-13.

20 Belen D, Simsek S, Yigitkanli K, Bavbek M. Internal reduction established by occiput-C2 pedicle polyaxial screw stabilization in pediatric atlantoaxial rotatory fixation. Pediatr Neurosurg. 2006;42(5):328-32.

21 Crossman JE, Thompson D, Hayward RD, Ransford AO, Crockad HA. Recurrent atlantoaxial rotatory fixation in children: a rare complication of a rare condition: report of four cases. J Neurosurg. 2004;100:307-11.

22 Dahdaleh NS, Dlouhy BJ, Menezes AH. Onestep fixation of atlantoaxial rotatory subluxation: technical note and report of three cases. World Neurosurg. 2013;80(6):e391-5.

23 Goto S, Mochizuki M, Kita T, Murakami M, Nishigaki H, Moriya H. Transoral joint release of the dislocated atlantoaxial joints combined with posterior reduction and fusion for a late infantile atlantoaxial rotatory fixation. A case report. Spine. 1998;23(13):1485-9.
24 Govender S, Kumar KP. Staged reduction and stabilisation in chronic atlantoaxial rotatory fixation. J Bone Joint Surg Br. 2002;84(5): 727-31.

25 Hicazi A, Acaroglu E, Alanay A, Yazici M, Surat A. Atlantoaxial rotatory fixation-subluxation revisited: a computed tomographic analysis of acute torticollis in pediatric patients. Spine. 2002;27(24):2771-5.

26 Patel AJ, Boatey J, Muns J, Bollo RJ, Whitehead WE, Giannoni CM, et al. Endoscopic endonasal odontoidectomy in a child with chronic type 3 atlantoaxial rotatory fixation: case report and literature review. Childs Nerv Syst. 2012;28(11):1971-5.

27 Ishii K, Matsumoto M, Momoshima S, Watanabe $\mathrm{K}$, Tsuji $\mathrm{T}$, Takaishi $\mathrm{H}$, et al. Remodeling of $\mathrm{C} 2$ facet deformity prevents recurrent subluxation in patients with chronic atlantoaxial rotatory fixation: a novel strategy for treatment of chronic atlantoaxial rotatory fixation. Spine. 2011;36(4):E256-62. 